\title{
The Impact of the Offshore Wind Farm Switching Transient Operation on Power System
}

\author{
Tingting Wang, Elham Makram*, Ramtin Hadidi, Xufeng Xu \\ Electrical and Computer Engineering Department, Clemson University, Clemson, USA \\ Email: twang@clemson.edu, * $\underline{\text { makram@clemson.edu, rhadidi@clemson.edu, xufengx@clemson.edu }}$
}

Received 20 June 2014; revised 21 July 2014; accepted 4 August 2014

Copyright (C) 2014 by authors and Scientific Research Publishing Inc.

This work is licensed under the Creative Commons Attribution International License (CC BY). http://creativecommons.org/licenses/by/4.0/

(c) (i) Open Access

\begin{abstract}
In this paper, a practical method to establish Doubly Fed Induction Generator (DFIG)-based wind farm equivalent model for switching transient analysis is demonstrated. In order to verify this method, a 3.6 MW equivalent wind farm model is built. The steady state results and load switching results are verified with those of detailed models of four $0.9 \mathrm{MW}$ generators. Using this method, a model of $40 \mathrm{MW}$ wind farm, representing the capacity for a proposed South Carolina offshore wind farm is established. To study large wind farm switching transient impacts on a system, different switching operations such as cable energizing and three-phase faults at different locations in wind farm are investigated and their impacts on system are analysed. Finally, conclusions based on the switching cases are presented.
\end{abstract}

\section{Keywords}

Offshore Wind Farm, DFIG, Switching Transient, Load Switching, Capacitor Switching, Fault

\section{Introduction}

With the increasing concern about environmental constraints, economic pressure, and energy security requirements, the world energy demand has pushed utilities to invest in renewable energy sources such as wind, geothermal, hydropower, tides, waves, solar, and biomass. As one of alternatives to fossil fuels, wind power is clean, plentiful, and is a renewable energy. The wind power development in the world is soaring today. The capacity of world wind reached 273 gigawatts (GW) by the end of 2012 with 15\% increase after 2011 [1].

Offshore wind energy, with more stable and higher average wind speed and with less land occupation, will be

\footnotetext{
*Corresponding author.
}

How to cite this paper: Wang, T.T., Makram, E., Hadidi, R. and Xu, X.F. (2014) The Impact of the Offshore Wind Farm Switching Transient Operation on Power System. Journal of Power and Energy Engineering, 2, 14-24. 
the direction of future large-scale wind industry. In 1992, Vinde by Farm, the world's first offshore wind farm with 5 MW installation capacity was built in Denmark. Since then countries in the world have started moving wind industry into the ocean. 4600 megawatts of offshore wind farms had been installed by mid-2012 [1]; the majority of them are in Europe. Although the construction and maintenance are more expensive than onshore wind power today, the cost will fall as this industry matures. The National Renewable Energy Laboratory (NREL) estimates that US offshore winds have a gross potential generating capacity four times greater than the nation's present electric capacity [2]. Although there are no operating offshore wind farms in the United States, projects are under development in the wind-rich areas like the East Coast, Great Lakes, and Pacific Coast. In July 2008, US Department of Energy announced that under conservative assumptions about transmission, fossil fuel supply, and supply chain availability, the United States could feasibly build $54 \mathrm{GW}$ of offshore wind power by 2030 which would be part of $20 \%$ of wind energy goal [3]. South Carolina, as part of the eastern American coastline, possesses potential offshore wind energy over twice the amount of its state level consumption [4]. It aims to build up 80 MW offshore wind farm by 2014 as first stage in SC state water and would expect to extend extra $1 \mathrm{GW}$ offshore wind energy in federal water at the succeeding stages [2]. The impact of offshore wind farms, with large capacity and long distance to the shore on South Carolina transmission system has to be considered before their installation. The steady state analysis was previously studied for voltage violations and thermal limit purpose. This paper focuses on switching transient only.

Recently, failures because of switching transient or fault associated with wind farm have been reported [5] [6]. Because switching operations in a system occur frequently, it can be the source of transient overvoltage or inrush current, which causes stress on insulation material of equipment, malfunction of protection, shedding of load, or even damage of equipment which results in the instability of system. On the other hand, it would affect wind farm operation because of switching transient. Thus the impact of switching transient in power system with offshore wind farm is important to investigate. Offshore wind farms equipment and maintenance cost higher than onshore wind farms. However, there are several advantages in offshore wind such as the possibility of highspeed wind and less incidents. Relevant studies have been carried out in offshore wind farms such as Nysted offshore wind farm [7], which is based on fixed speed induction generators. In this paper, the DFIG-based offshore wind farm is studied.

Large power system electromagnetic transient studies require detailed modeling of specific parts, and the remaining parts of the system have to be reduced as equivalent impedance. The detailed models of wind farms are required for transient study. However, it is impossible to model each generator with detailed models for the largescaled wind farm because of simulation time constraint. On the other hand, the fact that offshore wind farms consist of large numbers of relatively small and identical generating units makes equivalent model possible. One of the most used equivalent models for wind farms is by aggregating wind generator units [8]-[11]. In this paper, a DFIG-based wind farm equivalent model is developed for switching transient operation analysis. After the equivalent model results are verified with detailed model, several switching operations are performed to study their impact on the connected transmission system. The transients are also analyzed in frequency domain.

This paper is organized in two parts: the first part is modelling offshore wind farm equivalent system, and the second part investigates the impact of switching transient operations in offshore wind farm on the transmission system. Finally, some concluding remarks are provided.

\section{Equivalent Wind Farm Model}

The method of modelling large scale wind farm discussed in this paper is based on the steady state performance as well as the transient performance. The model uses the machine parameters listed in Table 1 [12]. Each DFIG's capacity is 0.9 MW with the output voltage of $0.69 \mathrm{KV}$. This model uses a Synchronized Pulse-Width Modulation (SPWM) converter at the grid side to ensure the constant DC voltage for the rotor side converter, which is a Current Reference Pulse-Width Modulation (CRPWM) converter. The stator Flux Oriented reference Control (FOC) decouples the rotor current to control the DFIG output power and frequency [13]. Figure 1 shows the DFIG based wind energy converter system.

In this paper, grid connected offshore wind farms consist of a large number of identical wind generators, step-up transformers, submarine cables and offshore substation, as shown in Figure 2. The step-up transformer raises each DFIG output voltage from $0.69 \mathrm{KV}$ to $34.5 \mathrm{KV}$. In transformer modelling, saturation is also considered. All units are connected in parallel to the collecting bus. Wind power is transmitted to the offshore substa- 
Table 1. DFIG detailed model and equivalent model parameters.

\begin{tabular}{|c|c|c|}
\hline Parameter & Detailed DFIG & Equivalent DFIG \\
\hline MVA & 0.9 & $n \times 0.9$ \\
\hline$V_{\text {Stator }}(\mathrm{KV})$ & 0.69 & 0.69 \\
\hline$R_{s p u}$ & 0.0054 & 0.0054 \\
\hline$L_{\text {lspu }}$ & 0.1 & 0.1 \\
\hline$R_{\text {rpu }}$ & 0.00607 & 0.00607 \\
\hline$L_{l r p u}$ & 0.11 & 0.11 \\
\hline$L_{\text {mpu }}$ & 4.5 & 4.5 \\
\hline \multicolumn{3}{|c|}{\begin{tabular}{ll}
\cline { 2 - 3 } Gearbox & Rotor Converter Grid Converter
\end{tabular}} \\
\hline
\end{tabular}

Figure 1. The DFIG-based wind energy converter system.

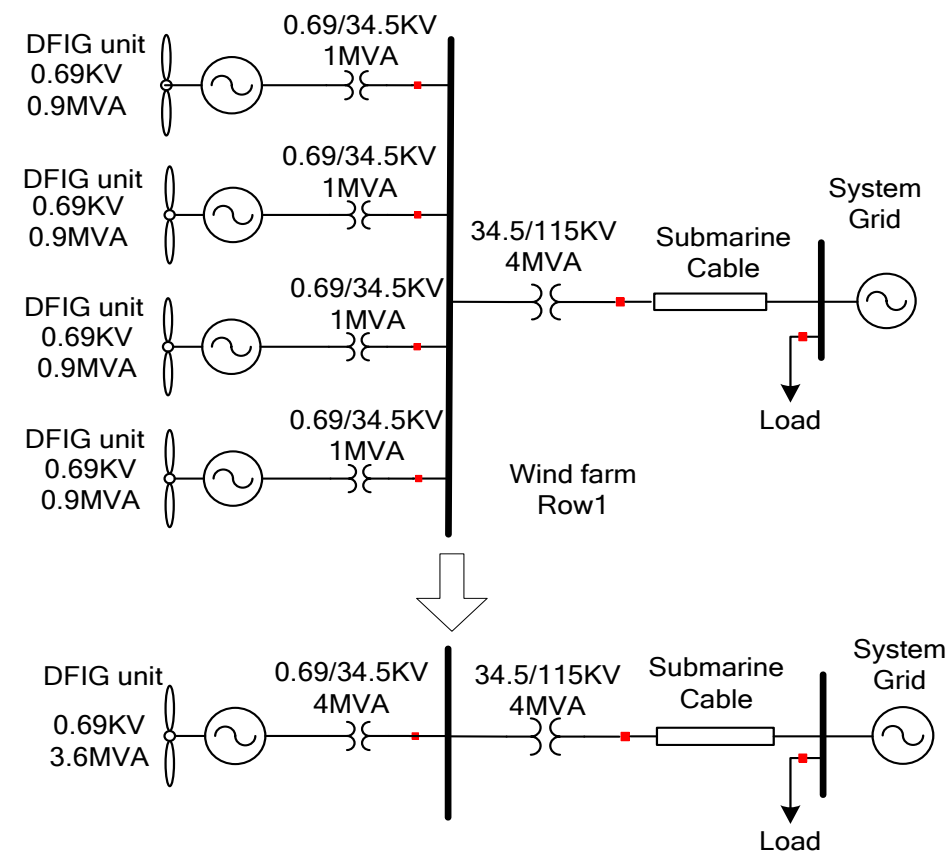

Figure 2. The wind farm configuration and aggregation.

tion, which steps up the voltage from $34.5 \mathrm{KV}$ to $115 \mathrm{KV}$ before its connection to the on shore interface bus. The submarine cables are simulated as the pi equivalent models in this paper.

\subsection{The Equivalent Model}

Equations (1) and (2) demonstrate the concept of the equivalent model.

$$
X_{\text {geq }}+X_{\text {teq }}=\frac{1}{n} \times\left(X_{g}+X_{t}\right)
$$




$$
\left(X_{\text {geq }_{-} p u}+X_{\text {tep }_{-} p u}\right) \times \frac{V_{\text {base }}^{2}}{n S_{\text {base }}}=\frac{1}{n}\left(X_{g_{-} p u}+X_{t_{-} p u}\right) \times \frac{V_{\text {base }}^{2}}{S_{\text {base }}}
$$

$X_{\text {geq }}$ and $X_{\text {teq }}$ represent the impedance of equivalent wind generator and the transformer impedance in real values, $X_{g}$ and $X_{t}$ represent impedance of one detailed wind generator and transformer impedance in real values, $X_{\text {geq_ pu }}$ and $X_{\text {tep_pu }}$ represent the impedance of equivalent wind generator and transformer in per unit values, $X_{g_{-} p u}$ and $X_{t_{-} p u}$ represent the impedance of one detailed wind generator and transformer in per unit values, $V_{\text {base }}$ and $S_{\text {base }}$ are the rated voltage and rated capacity of the detailed DFIG model, and $n$ represents the number of generators. As shown in Equations (1) and (2) the equivalent model has the same per unit parameter as a single machine. But the capacity of the equivalent model increases by $n$ times, as shown in Table $\mathbf{1}$. In detailed model, the control circuits, PWM signal generation and switches are modeled which are not included in the equivalent model.

The machine converter configuration of the equivalent model would be the same as the individual model. However, the control parameters need to be changed. The procedure is introduced in details in the next section.

\subsection{The Equivalent Model Derivation Procedure}

In this research, to develop equivalent model these steps are followed:

1) Use individual DFIG machine parameters (rotor and stator resistance and the reactance) in per unit for the equivalent model;

2) Increase the rating of individual DFIG by $n$ times for the equivalent model;

3) Calculate the equivalent machine steady state values based on the given machine parameters. According to the equivalent circuit in Figure 3, the Equations (3)-(15) [14] are used to calculate machine's reference value for control blocks. In the equations, $I_{r}, I_{s}, V_{r}, V_{s}, R_{s}, R_{r}$, represent the rotor side and stator side currents, voltages, and the resistors respectively; $L_{l m}$ represents the main flux-inductance of the stator; $L_{s}, L_{r}$, represent the inductance of stator side and the rotor side; $L_{s l}$ and $L_{r l}$ is the leakage inductance, $s$ is the slip of the machine, $\Phi_{r}$ and $\Phi_{s}$ are the phase flux linkages in the rotor and stator, and $\omega_{1}$ is the synchronous speed. $E_{r}$ ' represents the rotor voltage phasor (in stator coordinates), $P_{s}$ is the stator active power, $\varphi_{s}$ is the stator power factor angle, and $E_{1}$ is the self-induced electromagnetic force (EMF) by the stator winding with the rotor winding open [14];

4) Adjust the capacitor to provide smooth DC voltage for the rotor side converter shown in Figure 1;

5) Choose appropriate rating for the transformer at grid side converter according to the calculated rotor voltage;

6) Tune the PI controller's parameter for both rotor side current loop and grid side voltage loop for optimal transient study;

$$
\begin{gathered}
\Phi_{m}=L_{l m} I_{m} \\
I_{m}=I_{s}+I_{r} \\
\Phi_{s}=\Phi_{m}+L_{s l} I_{s}=L_{s} I_{s}+L_{l m} I_{r} \\
L_{s}=L_{s l}+I_{l m} \\
\Phi_{r}=\Phi_{m}+L_{r l} I_{r}=L_{r} I_{r}+L_{l m} I_{s}
\end{gathered}
$$

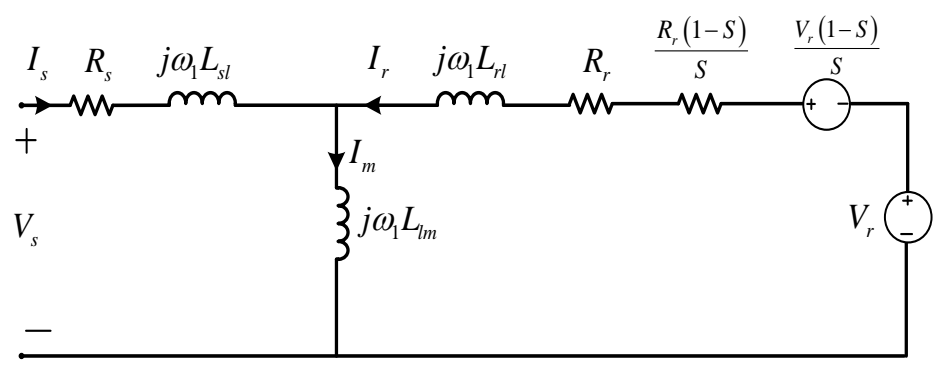

Figure 3. The equivalent circuit for DFIG steady state. 


$$
\begin{gathered}
L_{r}=L_{r l}+L_{l m} \\
I_{s} R_{s}-V_{s}=-j \omega_{1} \Phi_{s} \\
I_{r} R_{r}-V_{r}=-j \omega_{1} s \Phi_{r}=E_{r}^{\prime} \\
I_{s}\left(R_{s}+j \omega_{1} L_{s}\right)-V_{s}=E_{p}=-j \omega_{1} L_{1 m} I_{r} \\
I_{s}=\frac{P_{s}}{3 V_{s} \cos \varphi_{s}} \\
I_{r}=\frac{\Phi_{r}-L_{1 m} I_{s}}{L_{r}} \\
R_{r} \frac{L_{m}}{L_{r}} I_{s}+\left(\frac{R_{r}}{L_{r}}+j s \omega_{1}\right) \Phi_{r}=V_{r} \\
\left(R_{s}+j \omega_{1} L_{s}\right) I_{s}+j \omega_{1} \frac{L_{r}}{L_{m}} \Phi_{r}=V_{s}
\end{gathered}
$$

\section{Equivalent Model Verification}

In this section, four DFIG detailed models (0.9 MW each) are simulated to verify the equivalent model (3.6 MW) developed according to the previous section. All simulations are done in PSCAD environment [12]. The results are shown in Figures 4-6 to study the performance of the developed model during both steady state and transient operations. Load is switched on at the system interface bus for both models at $t=3 \mathrm{sec}$ when phase A voltage is at zero crossing at the steady state.

The active output power of two models is shown in Figure 4. The steady state results from 0 sec to 3 sec have negligible differences between the two models. When the load is switched on, the overshoot of the output power is followed by distortion which lasts for 2 sec before reaching at a new steady state. The maximum error between two models is 8.3\% for active power, as shown in Table 2. It should be noted that this model is developed for studying switching transients. It will require further refinements if stability analysis is concerned.

The phase voltage at the wind farm collection bus during load switching has a very small transient, as shown in Figure 5. The error between two models is shown in Figure 5 and it is less than $0.29 \%$.

The current of wind farm experiences overshoot before reaching a steady state condition is shown in Figure 6. The maximum error between two models from current point of view is $8.71 \%$ as illustrated in Table 2. As can be seen in Table 2, all errors are below 9\% which validates the developed equivalent model.

\section{The Switching Transient Impact of Wind Farm on an Existing Power System}

According to the method in the previous section, $40 \mathrm{MW}$ equivalent wind farm is established and connected to the Thevenin's equivalent of the South Carolina power system as shown in Figure 7. Wind power is generated

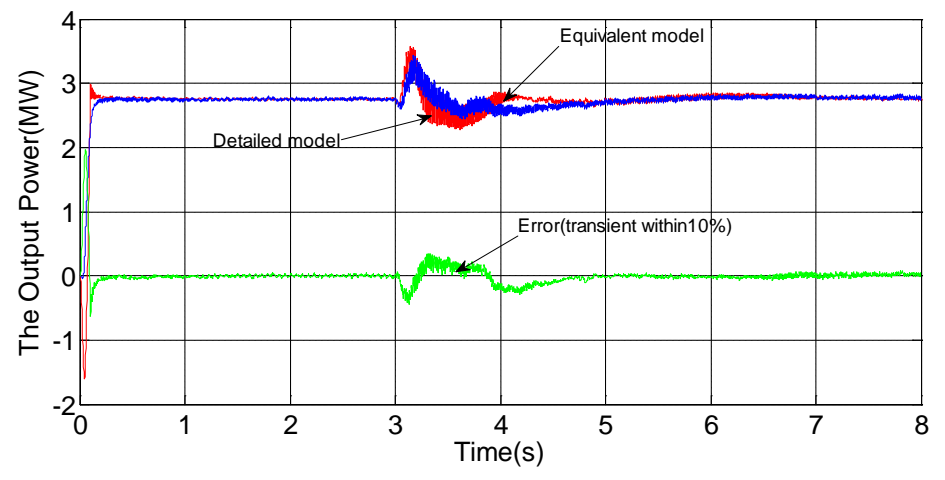

Figure 4. The output active power comparison between two models. 


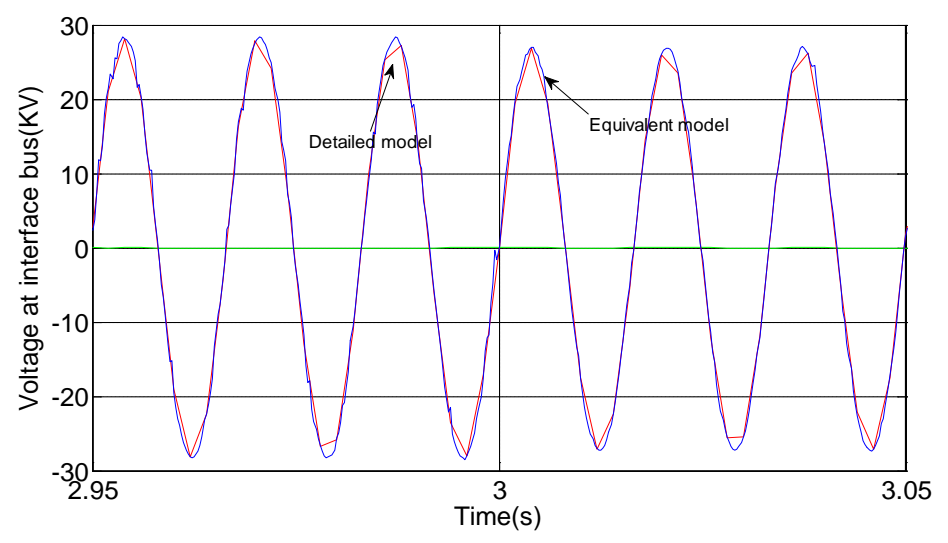

Figure 5. The interface bus voltage comparison between two models.

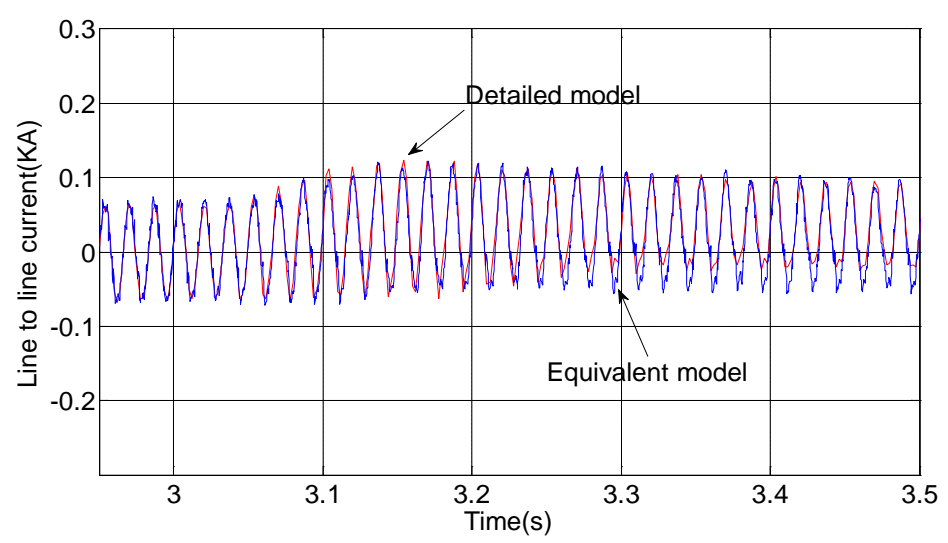

Figure 6. The wind farm interface bus current comparison.

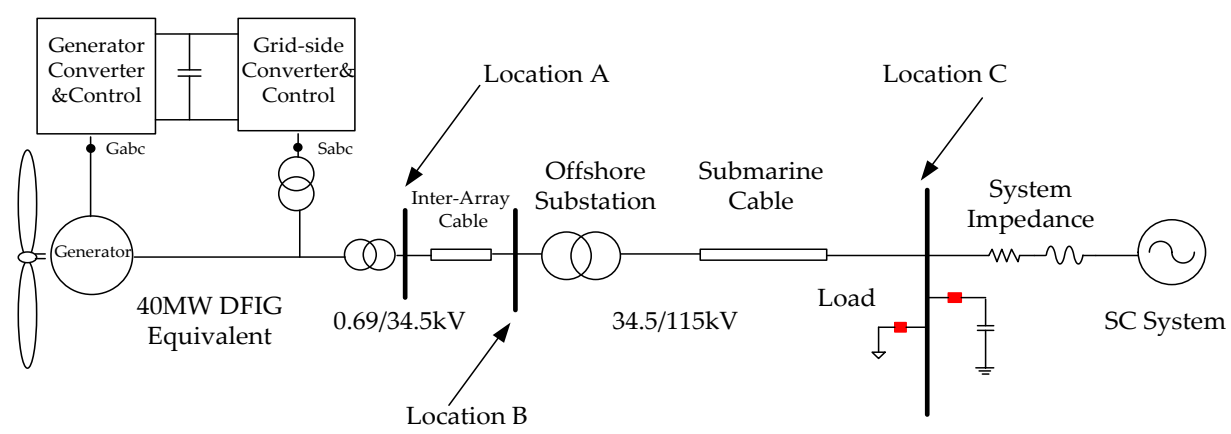

Figure 7.40 MW equivalent wind farm integration.

Table 2. The comparison of two models.

\begin{tabular}{cccc}
\hline Factors Considered & Voltage & Current & Power \\
\hline Max Error $\%$ & $0.29 \%$ & $8.71 \%$ & $8.3 \%$ \\
\hline
\end{tabular}

and delivered to offshore substation before its integration to system. The steady state voltage and current at the wind farm output bus are shown in Figure 8 and Figure 9.

The distortion because of DFIG converter can be observed at wind farm output voltage and current. The current output of the equivalent machine is analyzed using Fast Fourier Transform (FFT). It can be observed that 5th, 7th, and 11th harmonics exist and the Total Harmonic Distortion (THD) is $0.794 \%$, which is less than $1 \%$ of 
the fundamental frequency component, as shown in Table 3.

The power output of the equivalent wind farm with unity power factor is shown in Figure 10. The output power of DFIG can be adjusted by the wind speed and slip of each generator.

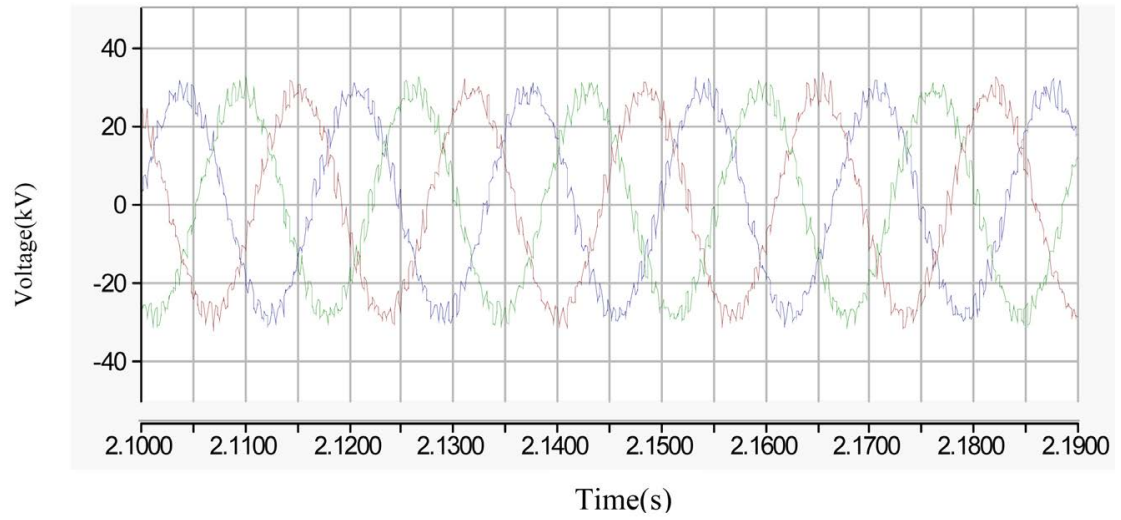

Figure 8. 40 MW equivalent wind farm output voltage.

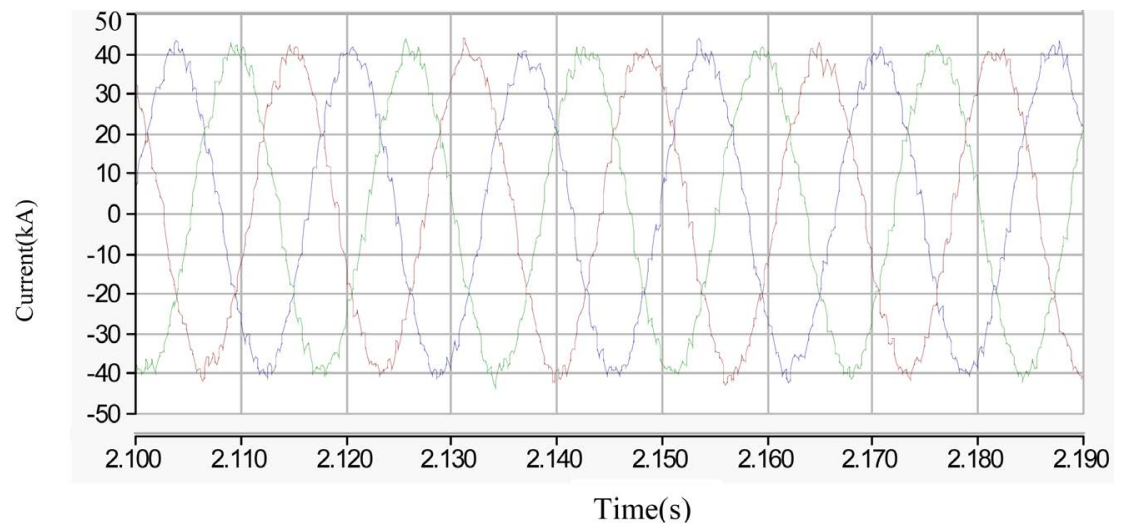

Figure 9.40 MW equivalent wind farm output current.

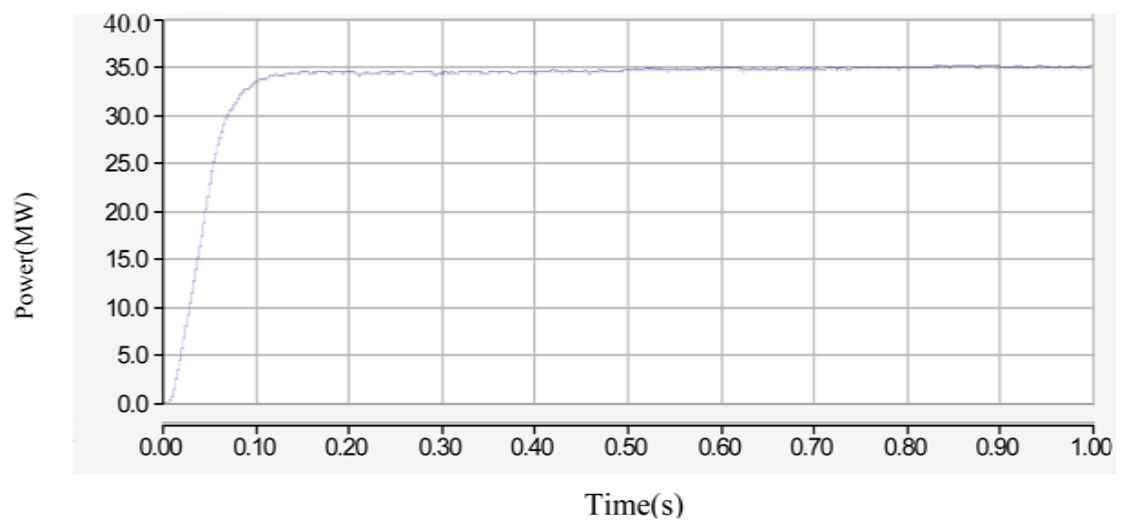

Figure 10. $40 \mathrm{MW}$ equivalent wind farm output power.

Table 3. The harmonic components in wind farm current.

\begin{tabular}{cccc} 
& Harmonic 5th & Harmonic 7th & Harmonic 11th \\
\hline$I_{h} / I_{\text {base }}$ & $0.30 \%$ & $0.60 \%$ & $0.425 \%$ \\
\hline
\end{tabular}




\subsection{Cable Energizing Results}

Cable energizing is a frequent operation inside wind farm. After the DFIGs are started-up and synchronized, they would be switched to the system. In Figure 11, new generators are added to the system to study the effect of a new cable switching. The new cable is switched at $t=3 \mathrm{sec}$. The offshore substation bus phase A voltage experiences voltage dip as the cable is switched on, as shown in Figure 12. Simulation results show that the more paralleled cables that are switched on, the more voltage decrease would occur at the substation bus.

\subsection{Three Phase Fault at Different Locations in the System}

Three phase faults in different locations in the wind farm would have different impacts on the system. In this paper, it is assumed that three phase fault occurs at the DFIG units output bus (location A), substation bus (location B), and system interface bus (location C), as shown in Figure 11. All faults occur at $t=3 \mathrm{sec}$ and last for $0.15 \mathrm{~s}$ before they are cleared.

The fault currents contributed by the wind farm for the fault at the different locations are shown in Table 4. The maximum fault current occurs when the fault is located at interface bus. The value reaches $68 \mathrm{kA}$. The minimum fault current occurs when the fault located at DFIG bus and it is $14.5 \mathrm{kA}$.

The contribution of the fault current from the wind farm is shown in Figure 13. The injected fault current by the wind farm reaches around 2.5 times of rated value when three phase fault occurs. When the fault is cleared, the largest recovery current injected from wind farm reaches around 4 times of rated value as shown in Figure 13.

The wind farm output power disturbance due to the fault at different locations is shown in Figure 14. As shown the generators are experienced fluctuation before the power reaches its steady state value. The maximum power output fluctuation of the wind farm occurs when a fault is located at the system interface bus whose overshoot reaches 71.25 MW (Table 4). The minimum power output fluctuation occurs when a fault is located at the DFIG output bus.

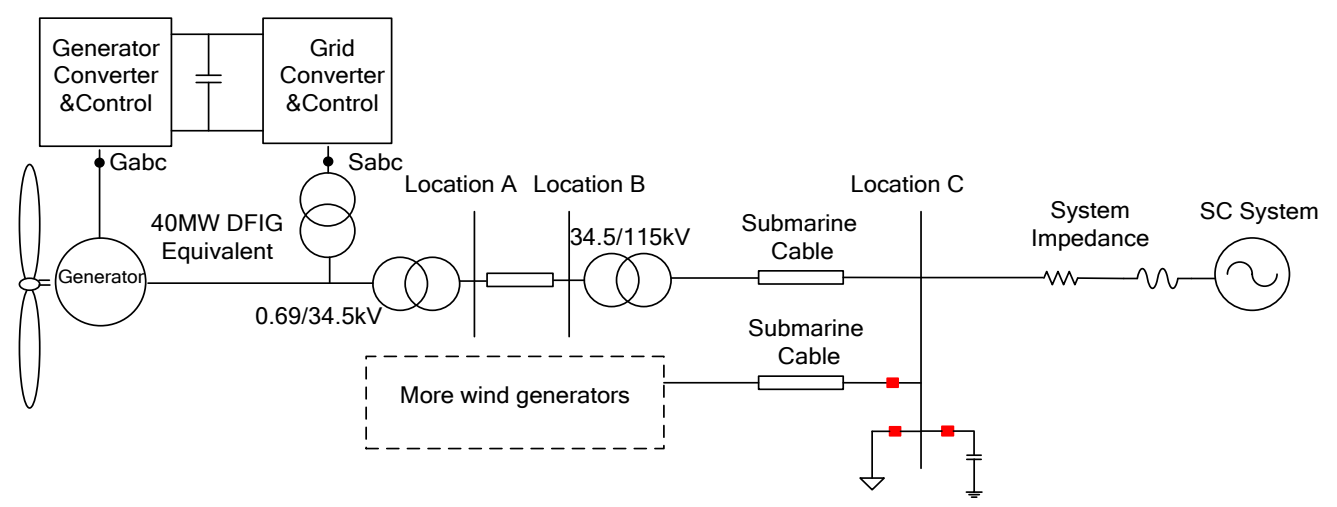

Figure 11. The cable energization in wind farm.

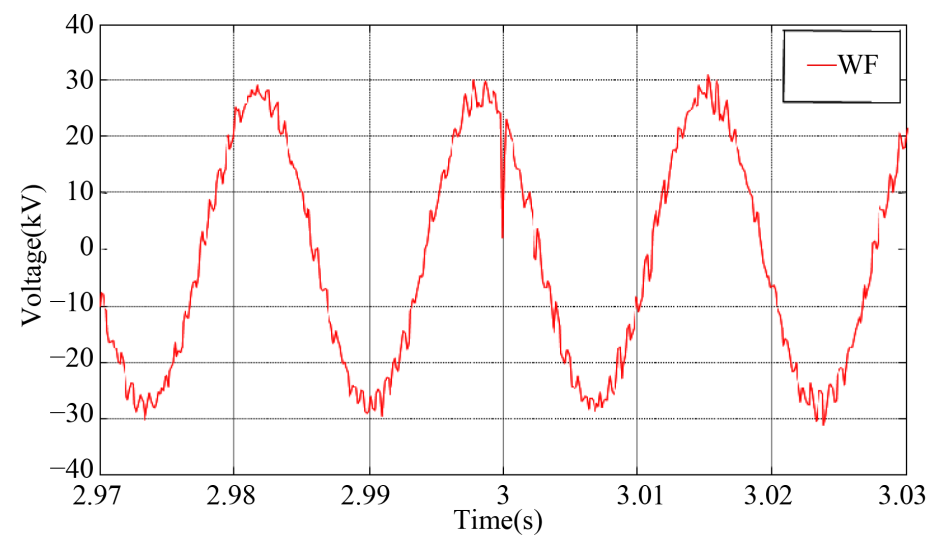

Figure 12. The voltage at substation when cable switching. 


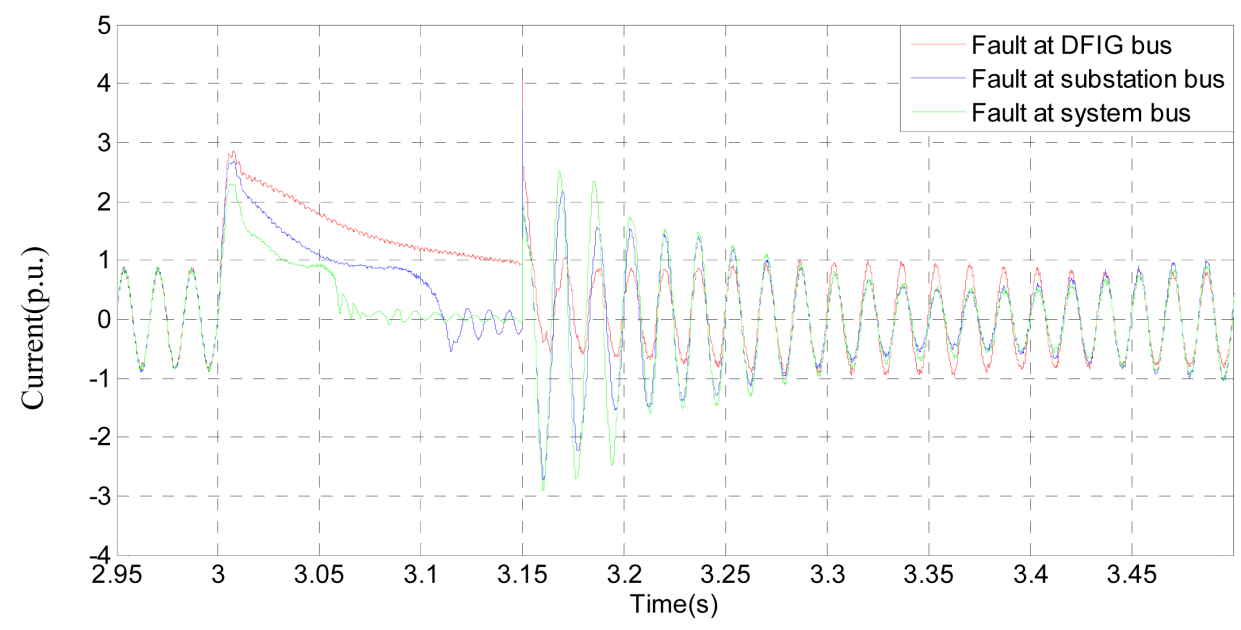

Figure 13. The contribution of the wind farm to fault current when three phase fault currents at different locations.

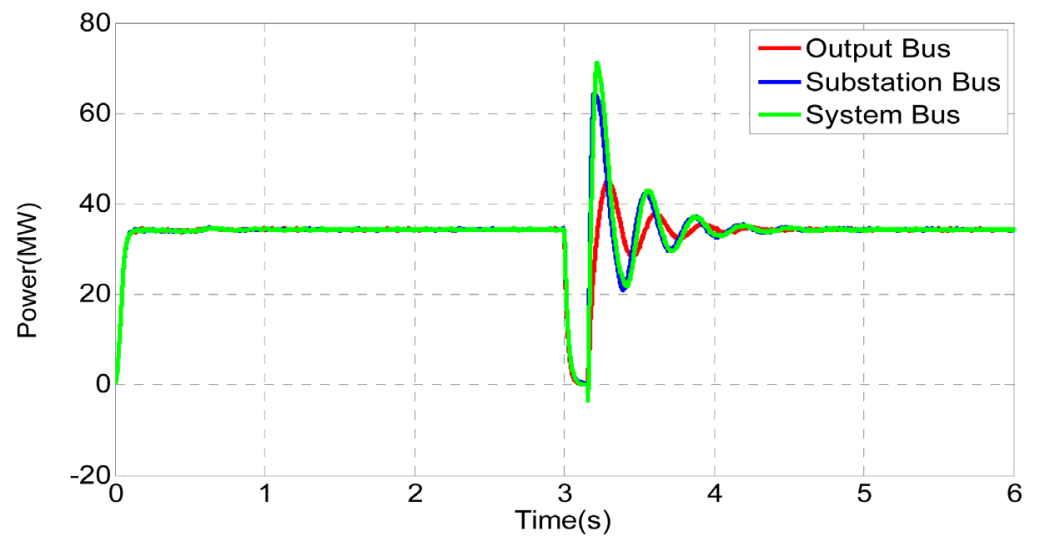

Figure 14. The output power of wind farm when faults occur at different locations.

Table 4. The comparison of three phase fault at different locations.

\begin{tabular}{cccc}
\hline Fault & $I_{\text {f } \max }(\mathrm{kA})$ & $P_{\max }(\mathrm{MW}) /$ Overshoot & $V_{\max }(\mathrm{RMS}) /$ Overshoot \\
\hline Location A & 14.5 & $45.2 / 31.03 \%$ & $0.98 /-2 \%$ \\
Location B & 19 & $64.5 / 86.96 \%$ & $1.01 / 1 \%$ \\
Location C & 68 & $71.25 / 106.52 \%$ & $1.07 / 7 \%$
\end{tabular}

The voltage drop at the wind farm output bus due to fault in different locations in the system is shown in Figure 15. The voltage dip during a fault can be affected by the capacitor bank in the DFIG converter. After the fault is cleared, the voltage reaches its steady state. The maximum over voltage happens when a fault is located at the system interface bus with $7 \%$ overvoltage. The minimum over voltage happens when a fault is located at the DFIG output bus.

Figure 16 illustrates the recovery voltage at the offshore substation bus when the fault is cleared at $t=3.15 \mathrm{~s}$ at three different locations. The maximum transient recovery voltage distortion happens when a fault is located at the system interface bus. The minimum transient recovery voltage distortion occurs when a fault is located at the DFIG output bus.

\section{Conclusion}

In this paper, the equivalent model for an offshore wind farm is developed and modelled. Small-scale equivalent 


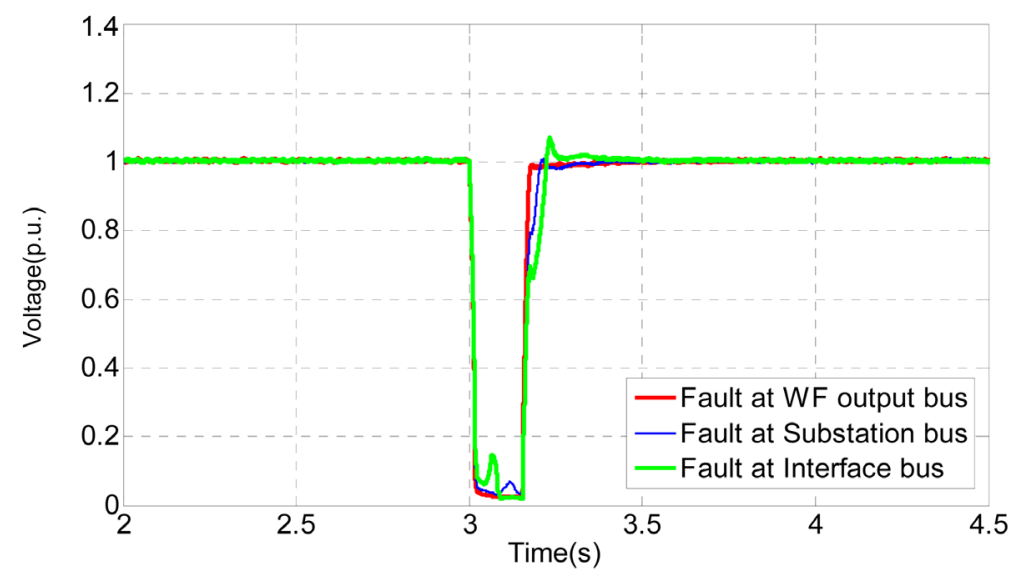

Figure 15. The RMS voltage at wind farm output bus when three phase fault at different locations.

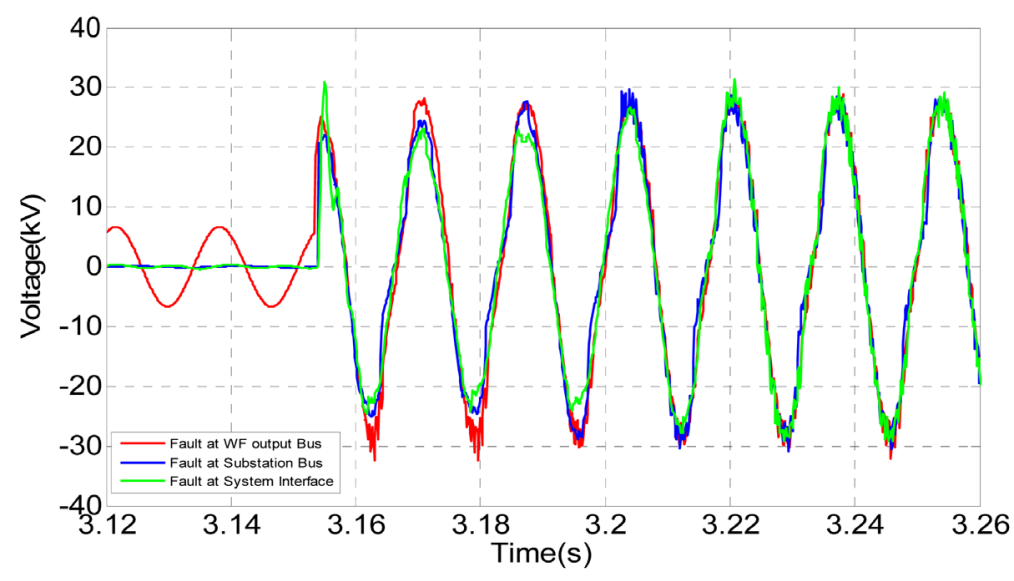

Figure 16. The recovery voltage at the wind farm output bus when faults cleared.

model is verified with the detailed model. Then a $40 \mathrm{MW}$ equivalent model is used to investigate switching operation for an offshore wind farm in South Carolina. Based on the simulation results it can be concluded that cable energizing causes voltage dip for the connected bus. The more paralleled cables are charged at the same time, the greater voltage dip at the connecting bus occurs. Different faults at different locations in wind farm are studied. The closer the fault location is to the system, the larger transient impact is observed at the system side.

\section{References}

[1] The World Wind Energy Association (2012) 2012 Half Year Report of World Wind Energy Association. www.wwindea.org

[2] Production Farms Feasibility Study Committee (2008) A Joint Resolution Requiring Recommendations from the Wind Energy Production Farms Feasibility Study Committee, South Carolina’s Role in Offshore Wind Energy Development. http://www.energy.sc.gov

[3] Musial, W. and Ram, B. (2010) Large-Scale Offshore Wind Power in the United States: Executive Summary. NREL Report No. TP-500-49229.

[4] Musial, W. and Ram, B. (2010) Large-Scale Offshore Wind Power in the United States: Assessment of Opportunities and Barriers. NREL Report No. TP-500-40745.

[5] Abbey, D. and Samson, G. (2008) Analysis of Transients in Wind Parks: Modeling of System Components and Experimental Verification. Master of Science Thesis, Chalmers University of Goteborg, Sweden.

[6] Christensen, L., Ulletved, M., Sørensen, P., Sørensen, T., Olsen, T., Nielsen, H., Sørensen, P. and Holmstrøm, O. (2007) GPS Synchronized High Voltage Measuring System. Nordic Wind Power Conference. 
[7] Ivan, A.A. (2008) Modeling of Switching Transients in Nested Offshore Wind Farm and a Comparison with Measurements EMT Simulations with Power Factory and PSCAD. Master of Science Thesis, DTU Electro Centre for Electric Technology (CET), Technical University of Denmark, Copenhagen.

[8] Fernandez, L.M., Garcia, C.A., Saenz, J.R. and Uredo, F. (2009) Equivalent Models of Wind Farms by Using Aggregated Wind Turbines and Equivalent Winds. Energy Conversion and Management, 50, 691-704. http://dx.doi.org/10.1016/j.enconman.2008.10.005

[9] Slower, J.G. and Kling, W.L. (2003) Aggregated Modeling of Wind Parks in Power System Dynamics Simulations. IEEE Power Tech Conference, 3, 626-631.

[10] Vladislav, A. and Hans, K. (2002) An Aggregate Model of a Grid-Connected, Large-Scale, Offshore Wind Farm for Power Stability Investigations-Importance of Windmill Mechanical System. Electrical Power and Energy System, 24, 709-717. http://dx.doi.org/10.1016/S0142-0615(01)00089-8

[11] Yang, L. and Zhan, X.P. (2009) Aggregating Wind Farm with DFIG in Power System Online Analysis. IEEE 6th International Power Electronics and Motion Control Conference, Wuhan, 17-20 May 2009, 2233-2237.

[12] PSCAD (2010) Manitoba Research Center “DFIG_2010_11.psc”. https://pscad.com/products/pscad/free_downloads

[13] Pena, R., Clare, J.C. and Asher, G.M. (1996) Doubly Fed Induction Generator Using Back-to-Back PWM Converters and Its Application to Variable-Speed Wind-Energy Generation. IEE Proceedings_Electric Power Applications, 143, 529-551.

[14] Ion, B. (2006) Variable Speed Generator. CRC Press, Boca Raton. 
Scientific Research Publishing (SCIRP) is one of the largest Open Access journal publishers. It is currently publishing more than 200 open access, online, peer-reviewed journals covering a wide range of academic disciplines. SCIRP serves the worldwide academic communities and contributes to the progress and application of science with its publication.

Other selected journals from SCIRP are listed as below. Submit your manuscript to us via either submit@scirp.org or Online Submission Portal.
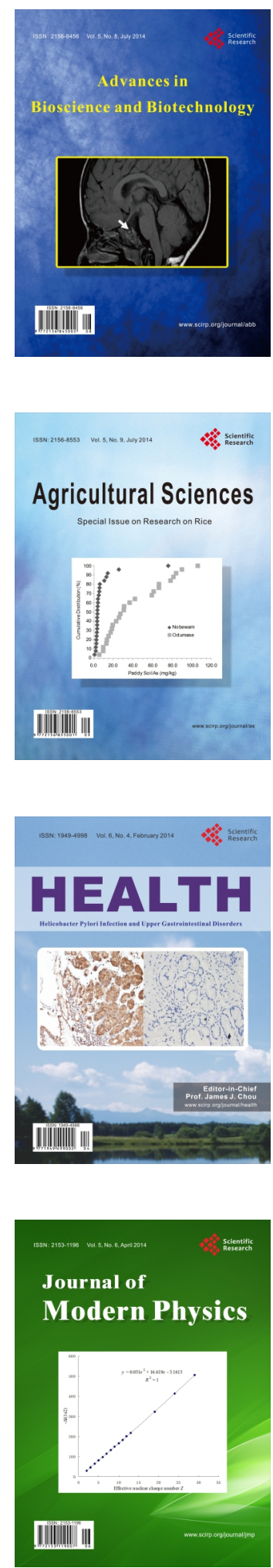
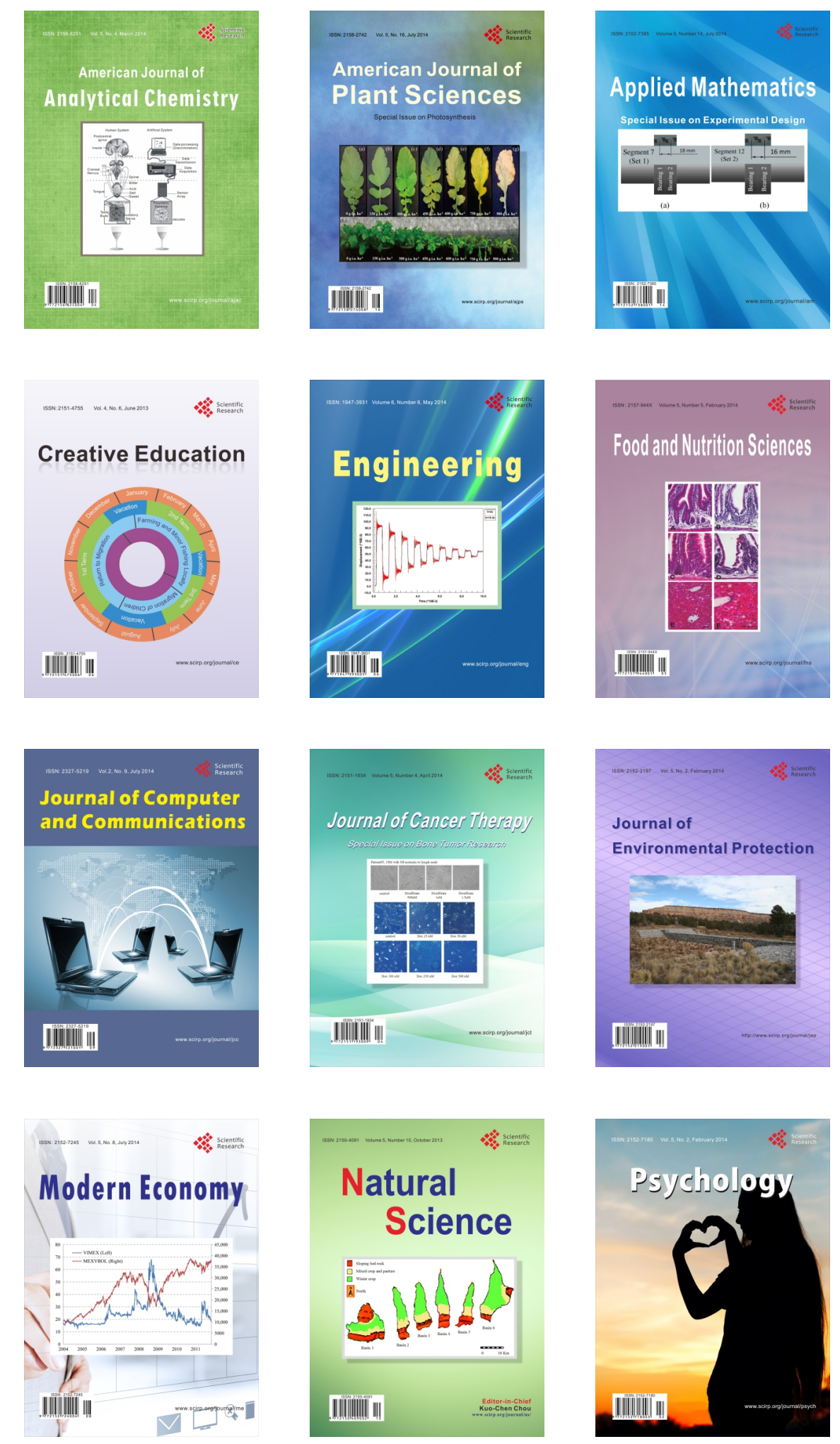